\title{
Investigation of aerosol particle size distributions in the San Diego Bay area by means of multi-band transmissometry
}

\author{
Arie N. de Jong, Alexander M.J. van Eijk, Marcel M. Moerman, Leo H. Cohen \\ TNO-Defense and Security, The Hague, The Netherlands
}

\begin{abstract}
The presence of atmospheric aerosols along the line of sight of infrared and electro-optical sensors greatly determines the range performance of these devices. On the one hand the aerosol particles scatter background (including sun) radiance into the field of view of the sensor, on the other hand they contribute to the atmospheric contrast reduction of the target. Proper knowledge of aerosol characteristics such as composition, concentration and size distribution is of vital importance for the prediction of their scattering and extinction characteristics. It is however found to be very difficult to collect accurate information on the particle size distribution (PSD) of aerosols. One of the reasons is the variation of the PSD along the path, which is likely to occur in a coastal area such as the San Diego Bay. One way to overcome these problems is the use of a multi-band transmissometer, as was done in previous measurement campaigns in the Baltic Sea [1] and in the Persian Gulf area [2]. The TNO seven-band optical/IR transmissometer system, providing path averaged transmission data for the intervening atmosphere, is operating at wavelengths between 0.4 and $14 \mu \mathrm{m}$.. In this spectral band, scattering in light hazy conditions is dominated by particles with a diameter of less than $4 \mu \mathrm{m}$. In order to simulate the transmission losses by scattering in various spectral bands a special calculation tool has been developed. This tool, described in this paper, allows detailed investigation of the possibilities of the retrieval of the PSD from multi-band transmission data. The slope in the plots of the transmission versus wavelength is directly related to the slope of the (lognormal) PSD plots (known as Junge exponent). The average transmission in a selected number of spectral bands is directly correlated to the average particle concentration (known as Junge coefficient). The principle of the methodology is illustrated with data collected during a measurement campaign, carried out over the San Diego Bay in August 2005. In this campaign we used six of the seven spectral bands, providing data over a $7.2 \mathrm{~km}$ over water path. It is shown that the retrieval method is very successful and the data correspond well with those, simultaneously collected with in-situ Particle Measurement Systems (PMS), located on both sides of the path. In addition to the path averaging, another advantage of the transmissometer PSD's, is the accuracy, being an order of magnitude higher than that of the PMS probes due to the fact that the measurement volume is more than a million times larger. A detailed analysis is given of the transmission data, showing peculiar effects were in the $2.3 \mu \mathrm{m}$ band around 19.00 UTC during most of the days. These effects are especially well illustrated in plots where the transmission in one spectral band is plotted against the transmission in another band for various times of the day.
\end{abstract}

KEYWORDS: atmospheric transmission, aerosols, scattering, particle size distribution

\section{INTRODUCTION}

The knowledge of aerosol characteristics is of key importance for the proper modeling of their scattering and extinction behavior, leading to contrast loss for IR and optical sensors, used for detection of long-range targets. In electro-optical sensor performance models such as EOSTAR [3], extinction by atmospheric aerosols is generally taken into account by using one of the standard MODTRAN atmospheres [4] and includes the Navy Aerosol Model (NAM) for maritime conditions. This NAM model is based upon a particle size distribution (PSD) with three log-normal modes. The centers of these modes are located at particle radii of $0.03 \mu \mathrm{m}, 0.23 \mu \mathrm{m}$ and $2.0 \mu \mathrm{m}$. It was found that the extinction coefficients, predicted with this type of PSD, did not fit the measurements in a number of occasions, such as during high wind speed and in coastal locations. Therefore the Advanced Navy Aerosol Model (ANAM) was developed [5], in which an additional log-normal mode is introduced at a particle radius of $8.0 \mu \mathrm{m}$ [6].

Atmospheric Optical Modeling, Measurement, and Simulation II, edited by Stephen M. Hammel, Anton Kohnle, Proc. of SPIE Vol. 6303, 63030L, (2006) · 0277-786X/06/\$15 · doi: 10.1117/12.680288 
As the amount of available transmission data for validation of ANAM in coastal regions is rather limited, it was very interesting to cooperate in August 2005 with SPAWAR San Diego in a transmission project over the San Diego Bay. This area was one of the focal points during the EOPACE program [7], carried out from 1995-2000. The San Diego Bay is well known for the rapid changing atmospheric conditions and for atmospheric inhomogeneities along the path. As can be seen in Figure 1, the measurement path is rather encapsulated by and partly protected from the Pacific Ocean. Zeisse [8] reports on a number of transmission anomalies due to refraction effects, while Doss-Hammel [9] introduces a model, describing quantitatively these effects. De Jong [10] presents results, showing that in the August/September period, the dominant transmission effects in the area are caused by aerosols in the early morning fogs. It was shown that prediction of the transmission via particle size measurements did not correspond to the real transmission data, at that event taken over a $15 \mathrm{~km}$ path from the US Naval Subase to the pier at Imperial Beach.

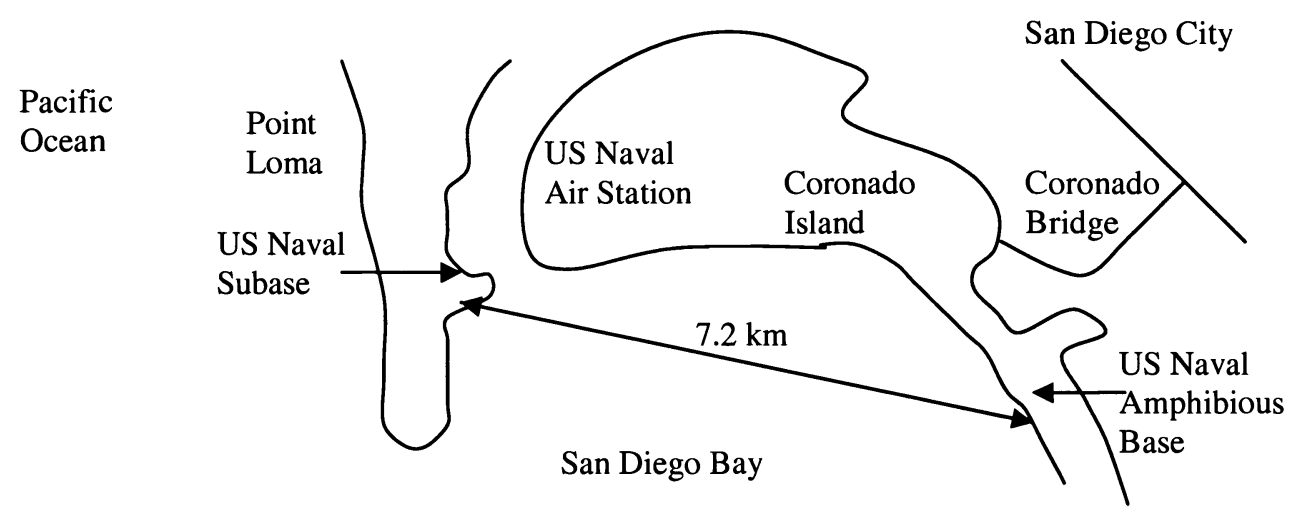

Figure 1. Situational sketch of the measurement path over the San Diego Bay during the August 2005 campaign

It was decided to use the Multi-Spectral Radiometer Transmissometer (MSRT), in a similar way as during the Vampira trials in the Baltic Sea in 2004 [1]. In addition it was decided to test an inversion technique to retrieve the PSD from the multi-band transmission data. A well-known way to retrieve PSD's indirectly is for example via the measurement of the phase function (aureole) at a number of wavelengths [11], [12]. This technique is used in connection with the AERONET network from NASA (hup://aeronet.gsfc.nalsil.gov), where the sun is used as source of radiation. The use of multispectral transmission data is well known for the characterization of battlefield smokes, because the results are directly related to the performance of the screening smoke [13]. Grassl [14] and Klett [15] introduce inversion techniques to obtain PSD's from measured multi-band transmission data. As Farmer [13] points out it is necessary to know the complex index of refraction of the particle material. Furthermore the method arrives in ambiguities if the number of particles with radii larger than $1 \mu \mathrm{m}$ becomes too big and if the wavelengths under consideration are getting too small, resulting in a fluctuating scattering cross section as function of $2 \pi \mathrm{R} / \lambda$.

In this paper we give in chapter 2 a description of the measurement set-up during the trials in San Diego in August 2005, including the optical characteristics of the multi-band transmissometer. Attention will be spent on the calibration and the transmission levels, to be expected for an aerosol-free atmosphere. Samples of representative data, which are composed of a mixture of molecular extinction and extinction by aerosols, are given in chapter 3. A description of the new retrieval method is given in chapter 4. The method is based upon Mie-scattering calculations for PSD's composed of three lognormal distributions, similar as in the NAM model, but with mode centers at radii of $0.09 \mu \mathrm{m}, 0.45 \mu \mathrm{m}$ and $2.25 \mu \mathrm{m}$ It will be shown, that the anomalous extinction in the $2.3 \mu \mathrm{m}$ band, found around 19.00 on each day, can be explained by assuming a special composition of this three distributions. Chapter 5 contains an application of retrieval method, applied to the data, presented in chapter 3. The resulting PSD's are compared with shore-based PMS data. Chapter 5 contains a comparison of PSD's retrieved by using three as well as four of the MSRT wavelengths: $0.45 \mu \mathrm{m}, 0.61 \mu \mathrm{m}, 0.91 \mu \mathrm{m}$ and $1.53 \mu \mathrm{m}$. Also attention is spent on the accuracy of the methodology and on the conditions of validity of the method. In chapter 6 a brief discussion is presented, together with some recommendations. 


\section{DESCRIPTION OF THE MEASUREMENT SET-UP}

For the set-up of our transmissometer in San Diego we could make use of the measurement range of SPAWAR over a path of $7.2 \mathrm{~km}$ from the US Naval Amphibious Base (source) to the US Naval Subase (receiver), nearly completely over water. Actually it was decided to use the same source as SPAWAR for their two band near-IR transmissometer. This source, developed at TNO, has a wide beam divergence and a lower radiant intensity than the double source, used in the VAMPIRA and $\mathrm{UAE}^{\wedge} 2$ campaigns ([1] and [2]). SPAWAR did replace the 18 lamps by a different type (Sylvania 50MR16/B/NSP11) as the original ones. The source [16], shown in Figure 2 (left), was mounted in a cabin together with some other equipment (Figure 2 middle) at a height of $6.4 \mathrm{~m}$ above mean sea level. The reference signal was sent to the Subase by a radio link from SPAWAR. The receiver (shown in Figure 2 right), located at a height of $11.6 \mathrm{~m}$ above mean sea level, was mounted outside the SPAWAR cabin at the Subase (Ballast Point). The alignment of the receiver, checked daily, was done with a two-axis tripod and an alignment telescope, to be mounted on top.
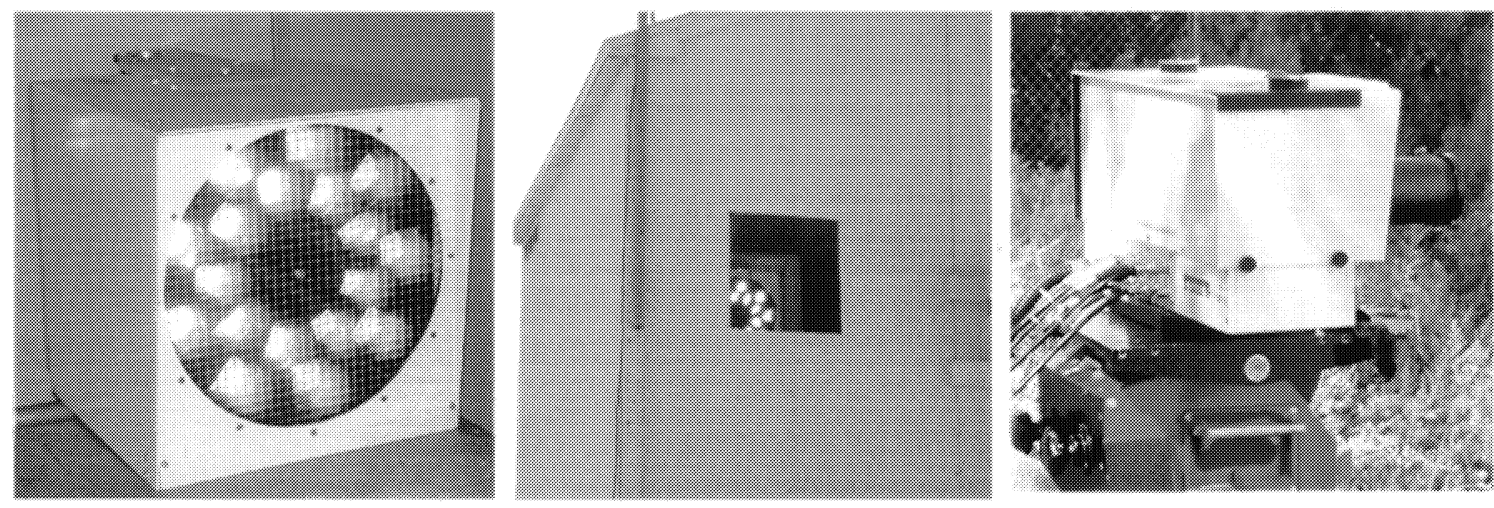

Figure 2 Pictures of the source used in San Diego (left), the cabin for the source (middle) and the MSRT receiver (right)

Table 1. Characteristics of the MSRT system including MODTRAN predictions $t_{\text {mol }}$ for an aerosol-free atmosphere with a path-length of $7.2 \mathrm{~km}$, an air temperature of $19{ }^{\circ} \mathrm{C}$ and a relative humidity of $80 \%$ and $\mathrm{t}_{\mathrm{mol}}{ }^{*} \mathrm{t}_{\text {aer }}$ for a visibility of $80 \mathrm{~km}$ and the source intensity $\mathrm{W}_{\mathrm{i}}$, deduced from the maximum signal value $\mathrm{V}_{\max }$ for each of the channels.

\begin{tabular}{|c|c|c|c|c|c|c|c|c|c|}
\hline $\begin{array}{c}\text { Chan- } \\
\text { nel }\end{array}$ & $\begin{array}{c}\text { Sp. band } \\
(\mathrm{FWHM})\end{array}$ & \multicolumn{2}{|c|}{$\begin{array}{c}\text { Receiver } \\
\text { Optics }\end{array}$} & $\begin{array}{c}\text { Resp. } \\
\mathrm{r}\end{array}$ & $\begin{array}{c}\text { Noise } \\
\mathrm{N}\end{array}$ & $\mathrm{t}_{\mathrm{mol}}$ & $\mathrm{t}_{\mathrm{mol}} *_{\mathrm{aer}}$ & $\begin{array}{c}\mathrm{V}_{\max } \\
(\mathrm{mV})\end{array}$ & $\mathrm{W}_{\mathrm{i}}(\mathrm{pp})$ \\
\hline No & $\mu \mathrm{m}$ & $\begin{array}{c}\text { FOV } \\
\mathrm{mrad}\end{array}$ & $\begin{array}{c}\mathrm{D} \\
\mathrm{mm}\end{array}$ & $\begin{array}{c}\mathrm{kV} / \mathrm{W} / \mathrm{m}^{2} \\
@ \mathrm{G} 1\end{array}$ & $\begin{array}{c}\mu \mathrm{V}(\mathrm{RMS}) \\
@ \mathrm{G} 1\end{array}$ & no aer. & $\begin{array}{c}80 \mathrm{~km} \\
\text { visib. }\end{array}$ & $@ \mathrm{G} 1$ & $\mathrm{~W} / \mathrm{sr}$ \\
\hline 1 & $0.40-0.49$ & 21.2 & 38 & 1.37 & 11.5 & 0.82 & 0.61 & 0.44 & 16.6 \\
\hline 2 & $0.57-0.65$ & 22.5 & 38 & 6.78 & 21 & 0.92 & 0.70 & 7.2 & 55 \\
\hline 3 & $0.78-1.04$ & 22.5 & 38 & 7.79 & 20 & 0.74 & 0.58 & 44 & 293 \\
\hline 4 & $1.39-1.67$ & 25.0 & 38 & 14.6 & 42 & 0.52 & 0.43 & 32 & 114 \\
\hline 5 & $2.12-2.52$ & 25.0 & 16 & 0.394 & 4.6 & 0.59 & 0.53 & 0.7 & 92 \\
\hline 6 & $3.55-4.15$ & 16.0 & 55 & 14.9 & 16 & 0.66 & 0.61 & 5.7 & 19.8 \\
\hline 7 & $7.8-13.7$ & 26.7 & 75 & 0.355 & 5.3 & & & - & - \\
\hline
\end{tabular}

The characteristics of the system are presented in Table 1. They include the spectral band at Full Width Half Maximum (FWHM), the Field of View (FOV) of the receiver, the lens diameter D, the responsivity $r$ (as DC Volts after the LockIn-Amplifier) and the noise level $\mathrm{N}$ (after Lock-In). For the range of $7.2 \mathrm{~km}$ the atmospheric transmission $\mathrm{t}_{\mathrm{mol}}$ is given for an average absolute humidity of $13.1 \mathrm{~g} / \mathrm{m}^{3}$ as predicted by MODTRAN. It was found that this condition was nearly 
constant within $+/-5 \%$ during the two weeks of our measurements. We also measured the maximum signal level $\mathrm{V}_{\max }$ for the conditions of best visibility $(80 \mathrm{~km})$ and ran again MODTRAN while using NAM with Air Mass Parameter (AMP) 3 to obtain $\mathrm{t}_{\mathrm{mol}} * \mathrm{t}_{\mathrm{aer}}$. This procedure provided us the calibration method for other atmospheric conditions. The measured Voltage level is reduced to the Voltage level $\mathrm{V}$ at Gain 1 . The atmospheric transmission $\mathrm{t}$ is then simply obtained from the relation: $t=t_{m o l} * t_{\text {aer }} * V / V_{\text {max }}$. When we want to know the transmission level, just caused by aerosols, we simply take the ratio: $t / t_{m o l}$. Table 1 finally contains the radiant intensity $\mathrm{W}_{\mathrm{i}}$ of the source, calculated from the value of $\mathrm{V}_{\max }$, the responsivity $\mathrm{r}$ (both at Gain 1) and the range of $7.2 \mathrm{~km}: \mathrm{W}_{\mathrm{i}}=\mathrm{V}_{\max } *\left(7.2 * 10^{3}\right)^{2} / \mathrm{r}$. It appears that the modified source gives about 3 times less radiant intensity at $1.5 \mu \mathrm{m}$ and about 3 times more radiant intensity at $4 \mu \mathrm{m}$ than the original source, described in [16]. The other channels have about the same radiant intensity in both cases. It is noted, that the modulation frequency of the source was $700 \mathrm{~Hz}$ in stead of the frequency of $800 \mathrm{~Hz}$ of the narrow beam source, used in [1] and [2]. The integration time of the Lock-In Amplifiers was 1.1 s.

\section{SAMPLES OF MEASURED DATA}

We start with the presentation of the transmission data for two periods of four and a half days in Figures 3 and 4 . The figures show the plots for the wavebands around $0.61,2.32$ and $3.85 \mu \mathrm{m}$, where the molecular extinction is removed. We have also corrected the data for the signal interruptions by sailing boats (about $1 \mathrm{~s}$ ) and bigger ships (about $30 \mathrm{~s}$ ). This was done by replacing the missing data by the average of the preceding and following measurement points. In order to reduce the strong fluctuations due to air turbulence (scintillation) the data were averaged over two minute periods. The plots show the time (16 August) of maximum transmission (best visibility), where we took the calibration. It is noted, that the transmission plots in the bands 1-4 followed each other in a very smooth way, which is illustrated clearly for the data on 20 and 21 August in Figure 5. Apparently the conditions varied during the campaign in such a way, that a variety of transmissions by aerosols between 0.00 and more than 0.70 occurred for the $0.61 \mu \mathrm{m}$ band. The lowest transmission values were found around 15.00 (UTC) which is 08.00 (morning) local time. The $3.85 \mu \mathrm{m}$ channel shows the least variation in transmission value, as may be expected from previous local measurements of PSD's. It is noted, that the wind speed stayed generally below $5 \mathrm{~m} / \mathrm{s}$, going down to a few $\mathrm{m} / \mathrm{s}$ at night, so that the number of bigger particles from waves was low. The wind was blowing most of the time from westerly directions, which means, that the measurement path was partly in the wind shadow of the peninsula of Point Loma. A peculiar transmission effect can be found in the $2.32 \mu \mathrm{m}$ channel, where most of the days a transmission dip occurs around 19.00 (UTC), which effect is not found in the four channels 1-4. One way to visualize this effect is to plot the transmission in the $2.32 \mu \mathrm{m}$ band as a function of the transmission in the $0.61 \mu \mathrm{m}$ band. For the data on 17 and 20 August this is shown in Figure 6. Apparently during the day, both the PSD and the particle density are changing in such a way, that the data are following a kind of looping in the diagram. Similar plots would appear, if we took the other shorter wavelength bands in stead of the $0.61 \mu \mathrm{m}$ band.

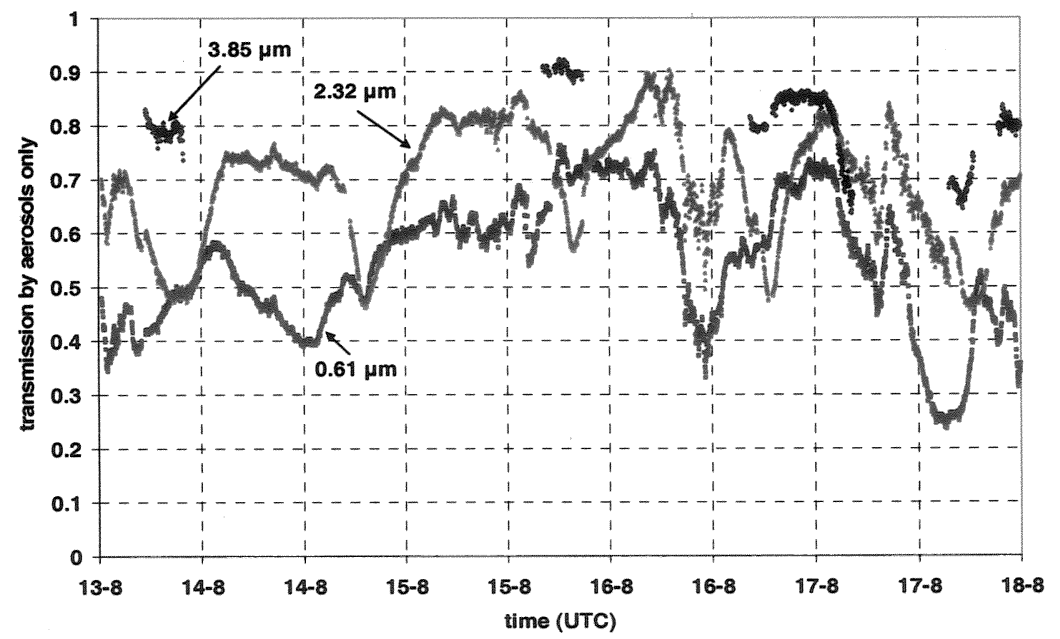

Figure 3. Transmission plots (aerosols only) for three of the seven channels from 13-17 August 2005 


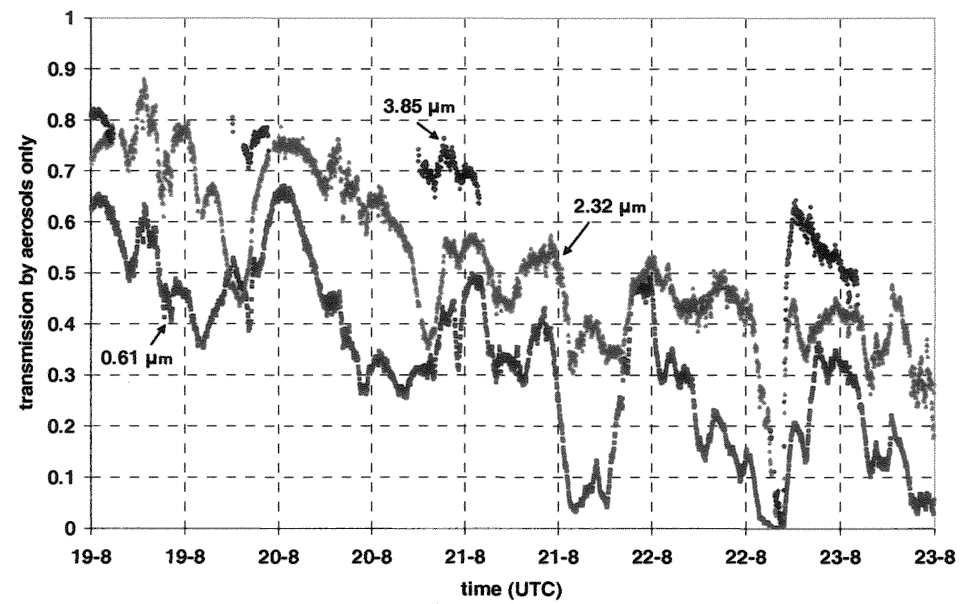

Figure 4. Transmission plots (aerosols only) for the period from 19-23 August 2005

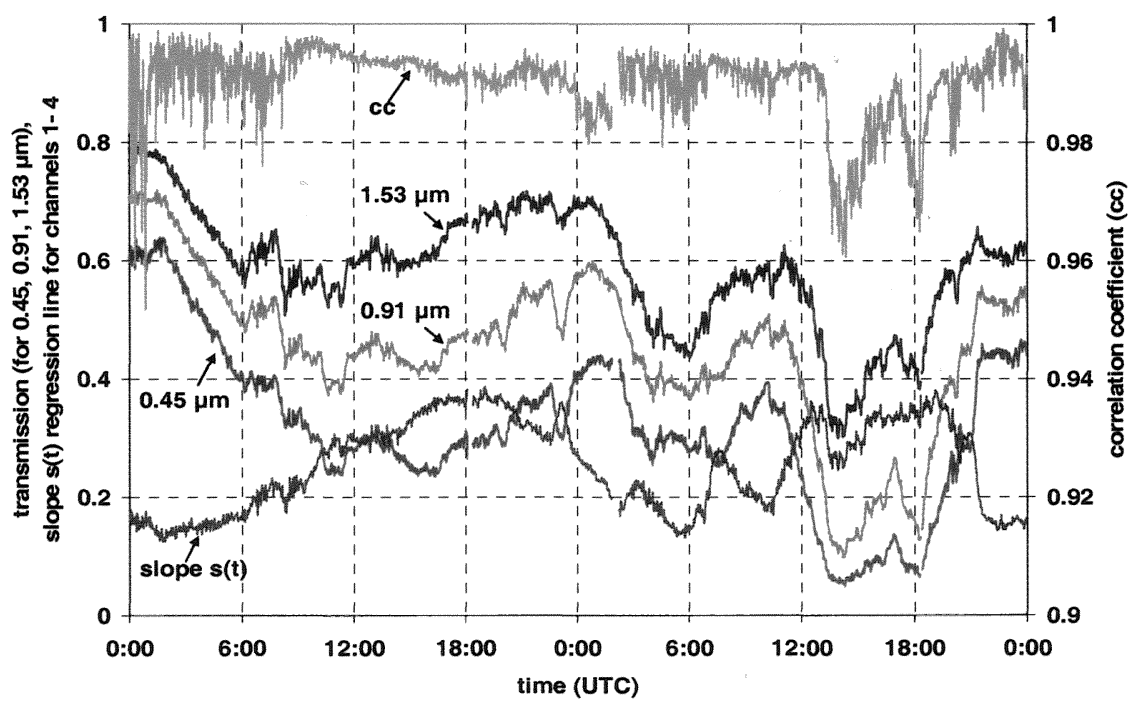

Figure 5. Transmission (aerosols only) plots for three channels, the slope $s(t)$ of the regression line for channels $1-4$ and the correlation coefficient $\mathrm{cc}$ for the data on 20 and 21 August 2005

The plots in Figure 5 show in more detail the transmission plots for the channels 1,3 and 4 during 20 and 21 August. One should note the high degree of correlation: the signals follow in a quite similar way rapid changes in visibility, thanks to the high signal to noise ratio. The figure also shows the slope $s(t)$ of the regression line for each data point, which is directly correlated to the PSD. The value of the correlation coefficient is practically always above 0.96 , which is an indication of the absence of a large number of bigger particles (radius larger than $1 \mu \mathrm{m}$ ) with enhanced extinction for wavelengths around $1 \mu \mathrm{m}$. The maximum value of $\mathrm{s}(\mathrm{t})$ stayed below 0.4 , which can be interpreted in such a way, that the difference in transmission at the wavelengths 0.5 and $1.5 \mu \mathrm{m}$ is never more than $0.4(40 \%)$. One might expect, that this situation occurs, when the average transmission $\mathrm{t}(\mathrm{av})$ is about 0.4 (the transmission at the average wavelength, which is in this case, where we use 4 wavelengths, $0.875 \mu \mathrm{m})$. When $\mathrm{t}(\mathrm{av})$ is increasing to values higher than 0.5 or decreasing below 0.2 , the slope tends to decrease. For the one event, where $t(a v)$ went down to 0 because of the presence of rather dense fog, $s(t)$ turns down to 0 . The good signal to noise ration and the high value of the correlation coefficient stimulate the investigation of a method to retrieve the PSD from both $s(t)$ and $t(a v)$. In cases where one of the wavelengths is missing, one might take three wavelengths in stead of four. 

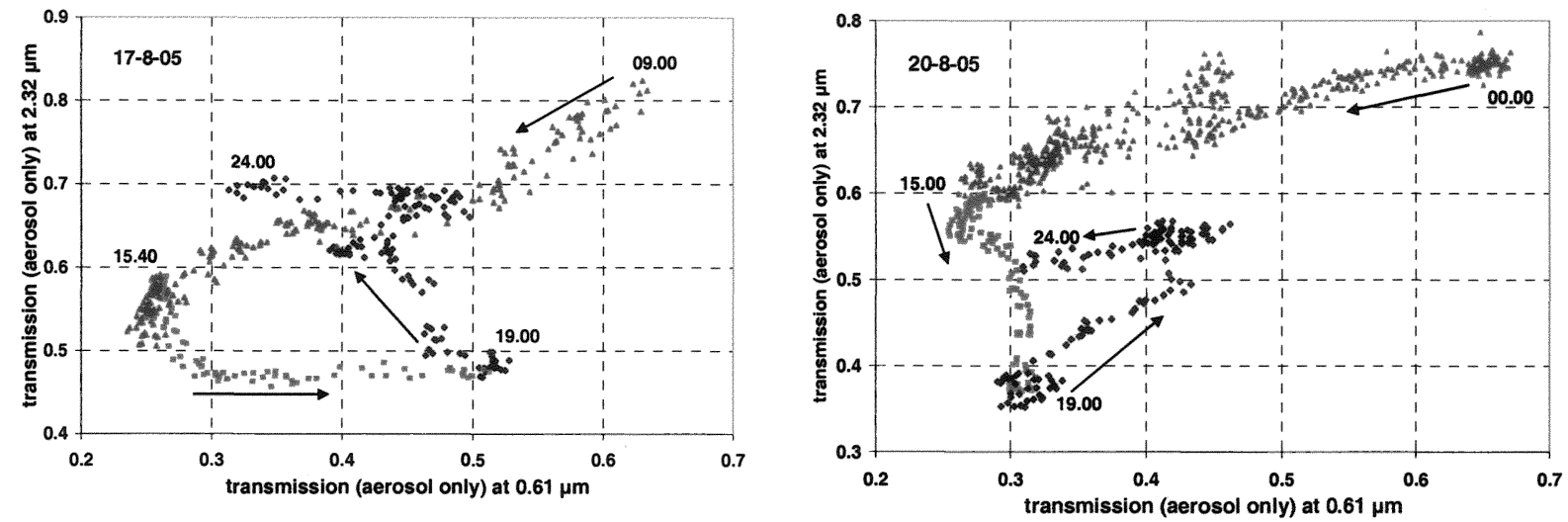

Figure 6. Plots of the transmission in the $2.32 \mu \mathrm{m}$ band vs. the transmission in $0.61 \mu \mathrm{m}$ band for 17 and 20 August 2005

\section{THE NEW RETRIEVAL METHOD}

In order to have some flexibility in the shape of the PSD's, we have introduced a combination of three log-normal distributions with variable amplitudes $A_{1}, A_{2}$ and $A_{3}$, variable widths $w_{1}, w_{2}$ and $w_{3}$, and radii centers $R_{1}, R_{2}$ and $R_{3}$ :

$$
\mathrm{dN} / \mathrm{dR}=10^{\mathrm{A}}{ }_{1} * \mathrm{~F}_{1} * \exp \left[-\left\{\ln ^{2}\left(\mathrm{R} / \mathrm{R}_{1}\right)\right\} / \mathrm{w}_{1}\right]+10^{\mathrm{A}}{ }_{2} * \mathrm{~F}_{2} * \exp \left[-\left\{\ln ^{2}\left(\mathrm{R} / \mathrm{R}_{2}\right)\right\} / \mathrm{w}_{2}\right]+10^{\mathrm{A}}{ }_{3} * \mathrm{~F}_{3} * \exp \left[-\left\{\ln ^{2}\left(\mathrm{R} / \mathrm{R}_{3}\right)\right\} / \mathrm{w}_{3}\right]
$$

The normalization factor $F_{i}(i=1$ to 3$)$ is specified by: $F_{i}=\left\{R_{i}^{*}\left(\pi w_{i}\right)^{1 / 2 *} \exp \left(w_{i} / 4\right)\right\}^{-1}$. The extinction coefficient by Miescattering at a certain wavelength follows then after integration of $\mathrm{dN} / \mathrm{dR}$ together with the scattering efficiency factor over all particle sizes [17]. The calculation tool allows direct information on the scattering and on the total extinction coefficient per km path. Some examples, shown in Figure 7 show the usefulness of the tool. In the plots on the left, the transmission at five wavelengths (being the centers the spectral bands of the MSRT system) is shown as function of the variable amplitude $A_{3}$, while the other amplitudes are kept constant. As the radius center of this third mode is located at 3 $\mu \mathrm{m}$, the transmission at $2.32 \mu \mathrm{m}$ (for the $7.2 \mathrm{~km}$ path-length) is decreasing more rapidly than the transmission at the other four wavelengths. This is exactly what we saw happening around 19.00 (UTC) in Figures 3 and 4, what might be an indication of the appearance of this type of particles at that time of the day. In Figure 7 on the right, the PSD is varied, while moving in the plots from point 1 through 5,9 and 13 back to 1 . In the first part (1-5) we keep $A_{3}$ constant, while the PSD tilts around this point. In the second part (5-9) we keep $A_{1}$ constant and tilt the PSD in the other direction and so on. The loops, created in the transmission space, simulate the effects, shown for real conditions in Figure 6.
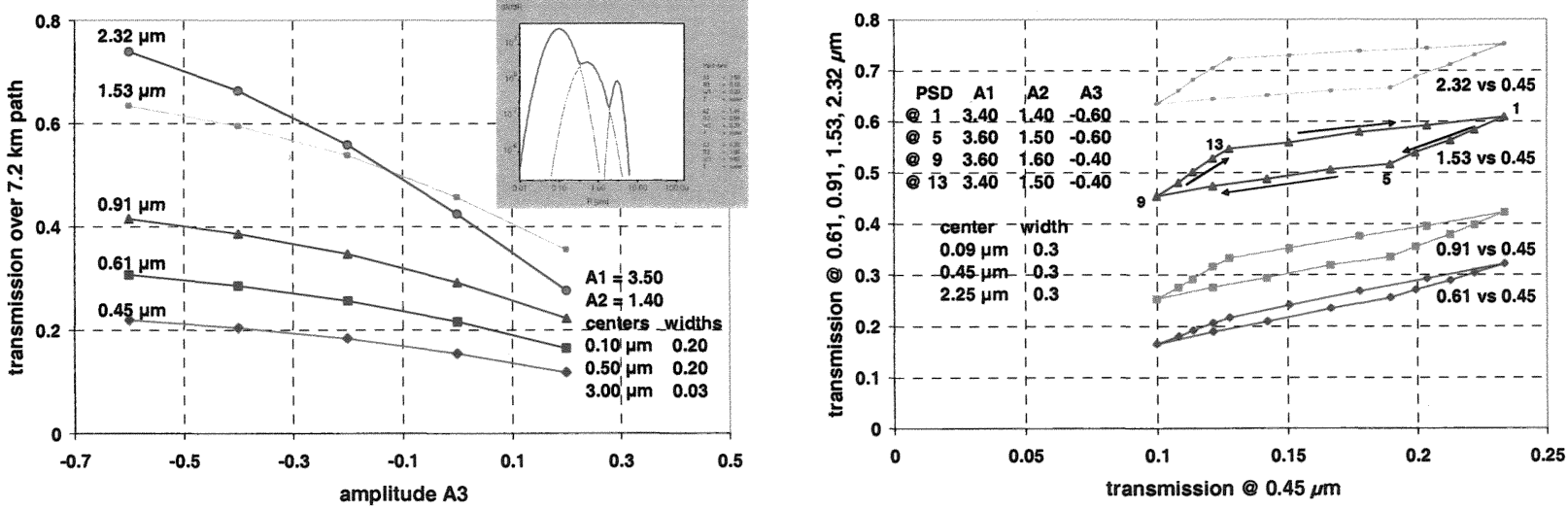

Figure 7. Examples of transmission calculations with the scattering calculation tool. Left: variation of amplitude $\mathrm{A}_{3}$; Right: effect of variation of the PSD on the ratio of the transmission at one wavelength versus another 
One should note, that these phenomena (variation of slope and concentration) occur frequently in real atmospheres. In order to convert measured average transmission $t(a v)$ and transmission slopes $s(t)$ into PSD properties we started by taking a variety of eight PSD slopes $\mathrm{s}(\mathrm{p})$, ranging from -4.23 to -2.60 . We also took a number of particle concentrations, (density) resulting in a variety of transmission levels from 0.056 to 0.087 at the average wavelength. For the three wavelengths: $0.61,0.91$ and $1.53 \mu \mathrm{m}$ the average wavelength is $1.02 \mu \mathrm{m}$ and for the four wavelength case the average wavelength is $0.875 \mu \mathrm{m}$. For the PSD's we took for the mode centers $R_{1}, R_{2}$ and $R_{3}$ respectively $0.09,0.45$ and $2.25 \mu \mathrm{m}$. The widths varied from 0.40 for the highest slope to 0.70 for the lowest slope. The amplitudes $A_{1}, A_{2}$ and $A_{3}$ were ranging around respectively 3.00, 1.20 and -0.60 . Two of the PSD's at two levels are shown in Figure 8 (left) The PSD curves follow parts of the lognormal distributions. The curves were approximated by their regression lines, simulating a standard Junge distribution. From the scattering coefficient, provided by the tool, the transmissions (by aerosols only) were calculated for the $7.2 \mathrm{~km}$ path. In this case we took the refractive indices of water. The results of these calculations are illustrated in Figure 8 (right) for three values of the PSD slope s(p): $-2.74,-3.34$ and -4.11 and for three values of the average transmission $\mathrm{t}(\mathrm{av}): 0.11,0.37$ and 0.65 .
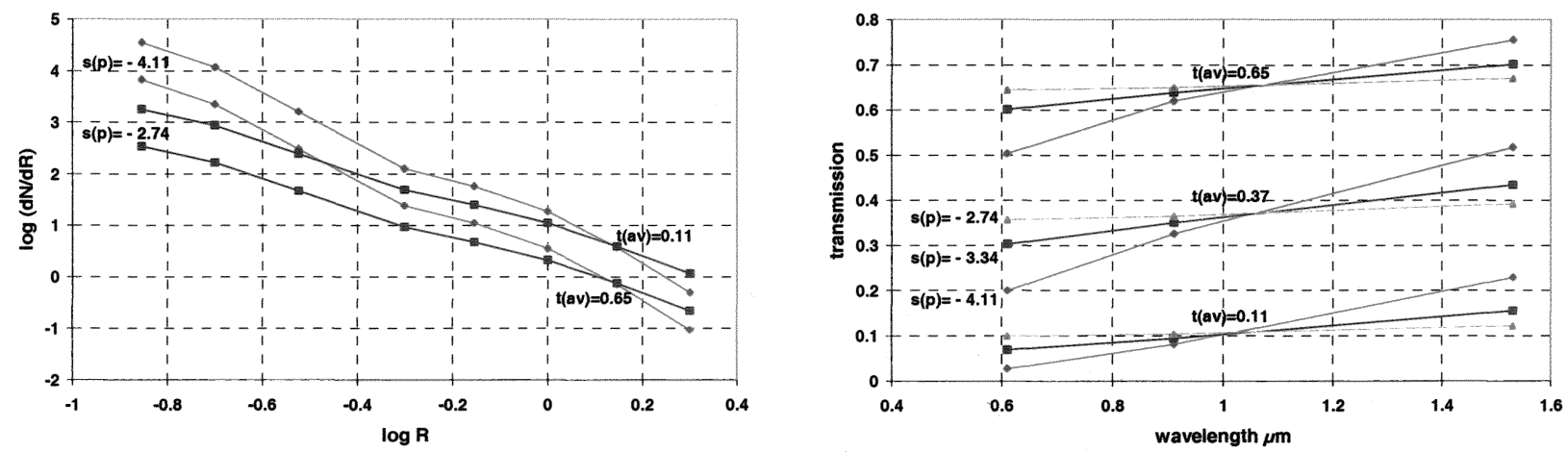

Figure 8. Example of two PSD slopes s(p) (-2.74 and -4.11) and two average transmissions t(av) $(0.11$ and 0.65$)$ at left; transmissions by aerosols at three wavelengths for three values of $s(\mathrm{p})$ and $\mathrm{t}(\mathrm{av})$ for $7.2 \mathrm{~km}$ path.
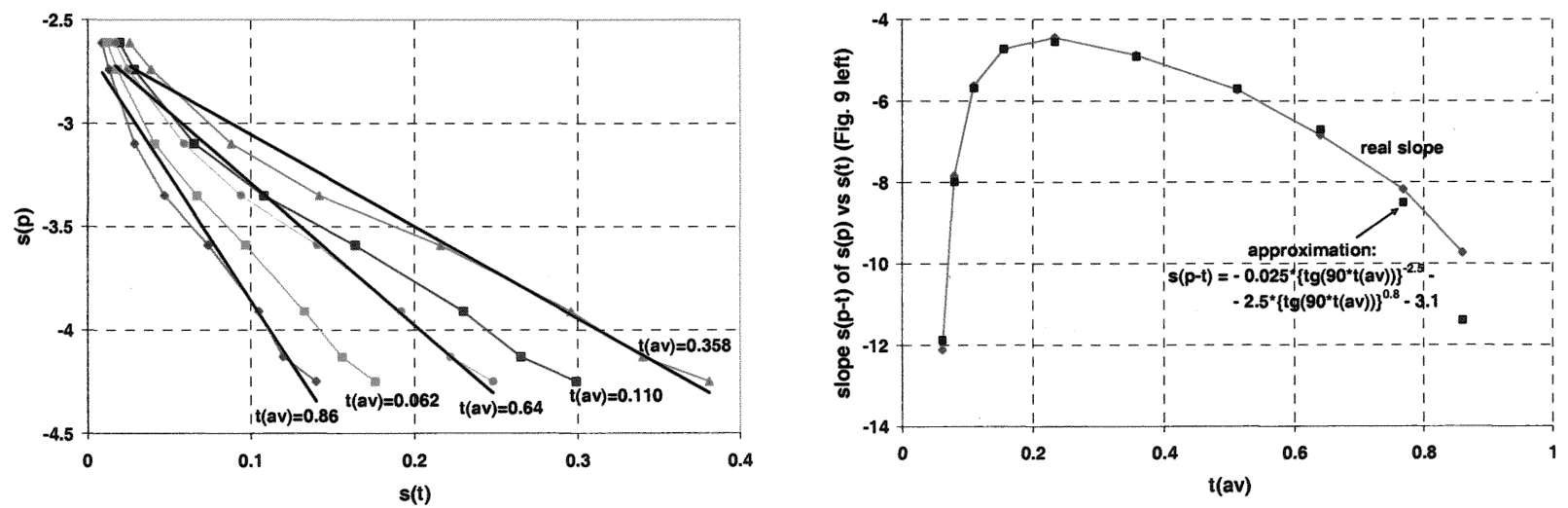

Figure 9. Left: variation of $s(p)$ with $s(t)$ at various levels $t(a v)$, resulting in a range of regression lines $s(p-t)$. Right: variation of $s(\mathrm{p}-\mathrm{t})$ with $\mathrm{t}(\mathrm{av})$, real values and approximated.

Next the regression lines $s(t)$ have been determined for all cases of $s(p)$ and $t(a v)$. Both the values of $s(p)$ and $s(t)$ have been plotted against each other for all the values of $t(a v)$. A number of these plots has been presented in Figure 9 (left). The associated regression lines $s(p-t)$ for the slopes are calculated (and shown for three of the curves), which shows that these lines all tend to converge at $s(t)=0$ to the value of -2.62 . So for $s(p)$ we may take: $s(p)=s(p-t) * s(t)-2.62$. It appears, as might be expected, that $s(p-t)$ varies with $t(a v)$ and the relationship is illustrated in Figure 9 (right). This relation has (for simplicity) with reasonable agreement been approximated by formula (2):

$$
\mathrm{s}(\mathrm{p}-\mathrm{t})=-0.025 *\{\operatorname{tg}(90 * \mathrm{t}(\mathrm{av}))\}^{-2.5}-2.5 *\{\operatorname{tg}(90 * \mathrm{t}(\mathrm{av}))\}^{0.8}-3.1
$$


This formula allows the direct calculation of $s(p-t)$ under the assumption, that the relation between $s(p)$ and $s(t)$ is a linear one, which is not fully correct, but not too bad, as is shown in the left part of Figure 9. The same calculations have been carried out for the four wavelength approach, which results in a slightly different formula for $s(p-t)$ :

$$
\mathrm{s}(\mathrm{p}-\mathrm{t})=-0.38 *\{\operatorname{tg}(90 * \mathrm{t}(\mathrm{av}))\}^{-1.2}-0.85^{*}\{\operatorname{tg}(90 * \mathrm{t}(\mathrm{av}))\}^{1.6}-2.9
$$

It is noted, that in both equations (2) and (3) for $\mathrm{s}(\mathrm{p}-\mathrm{t})$ the presence of the tg function may cause problems when the average transmission $t(\mathrm{av})$ approaches the values 0 and 1 . The probability, that $t(\mathrm{av})$ becomes 1 is very low, as in practice there will always be a certain amount of aerosols in the atmosphere. In cases of haze and fog however, transmissions may occasionally decrease to low values close to 1 , where the retrieval methodology may fail.Next we need to determine the value of $\log (\mathrm{dN} / \mathrm{dR}$ ) for a radius $\mathrm{R}=1 \mu \mathrm{m}$ (thus $\log \mathrm{R}=0$ ). As we propose that the PSD to be found follows a Junge distribution: $d N / d R=J_{c} * R^{\mathrm{Je}}$, with $\mathrm{J}_{\mathrm{c}}$ as Junge coefficient and $\mathrm{J}_{\mathrm{e}}$ as Junge exponent, we are aiming for $\log \left(\mathrm{J}_{\mathrm{c}}\right)$. In Figure 10 (left) we have plotted $\log \left(\mathrm{J}_{\mathrm{c}}\right)$ as function of $\mathrm{t}(\mathrm{av})$ for three values of $\mathrm{s}(\mathrm{p})$. It is found that there exists a slight dependence of the slope on the value of $s(\mathrm{p})$. Therefore we assume the following approximation for the relation between $\log \left(\mathrm{J}_{\mathrm{c}}\right)$ and $\mathrm{t}(\mathrm{av}): \log \left(\mathrm{J}_{\mathrm{c}}\right)=\mathrm{c} * \mathrm{t}(\mathrm{av})+\mathrm{d}$, where $\mathrm{c}$ and $\mathrm{d}$ are obtained from the second order polynomials through the points, delivered by Figure 10 (left) and shown in Figure 10 (right):

$$
\mathrm{c}=-0.0395 * \mathrm{~s}(\mathrm{p})^{2}-0.223 * \mathrm{~s}(\mathrm{p})-1.791 ; \mathrm{d}=-0.1626 * \mathrm{~s}(\mathrm{p})^{2}-1.2155 * \mathrm{~s}(\mathrm{p})-0.9698
$$

Actually the input value of $s(p)$ is equal to the Junge exponent $J_{e}$, just introduced. Relation (4) is valid for the three wavelength procedure. In the case of four wavelengths, formula (4) turns out to become:

$$
\mathrm{c}=-0.0695 * \mathrm{~s}(\mathrm{p})^{2}-0.395 * \mathrm{~s}(\mathrm{p})-1.916 ; \quad \mathrm{d}=-0.1696 * \mathrm{~s}(\mathrm{p})^{2}-1.2181 * \mathrm{~s}(\mathrm{p})-0.9651
$$
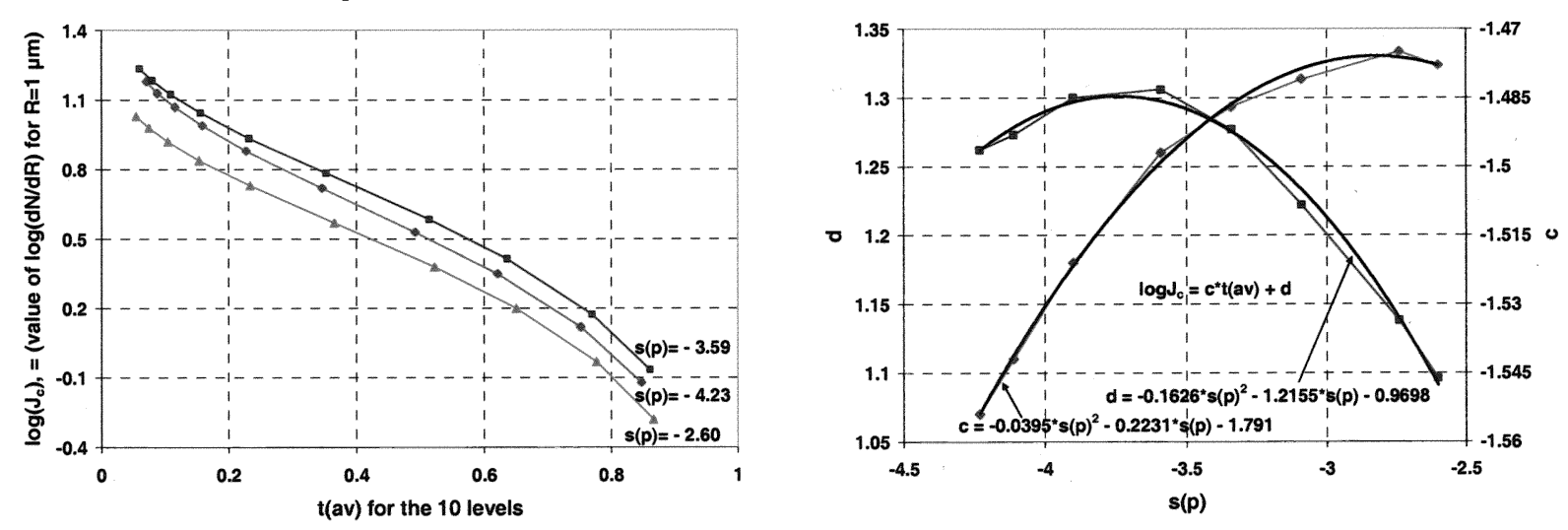

Figure 10. Relation between $\log \left(\mathrm{J}_{\mathrm{c}}\right)$ and $\mathrm{t}(\mathrm{av})$ (left) and way to obtain $\log \left(\mathrm{J}_{\mathrm{c}}\right)$ via interpolation from $\mathrm{s}(\mathrm{p})$ (right)

In summarizing we will repeat the different steps in the retrieval methodology, introduced in this chapter:

- Establish the collected transmission data, remove the outliers and make a choice if three or four wavelengths should be used, based upon the common behavior of the data

- Apply sufficient time-averaging of the data (in our case we apply an averaging time of two minutes), in order to smooth out rapid signal fluctuations due to atmospheric turbulences

- Calculate for each series of data points in time the regression line or slope $s(t)$ of the transmission values and also the transmission value for the average wavelength

- Calculate the slope $s(p-t)$ of the plots of the synthetic PSD curve $s(p)$ versus $s(t)$ with the help of formula (2) for the three wavelength and (3) for the four wavelength approach

- Calculate the real value of $s(p)$, which is equivalent to the value of the Junge exponent $J_{e}$, by means of the relation: $s(p)=s(p-t) * s(t)-2.62$

- Calculate the values of the coefficients $c$ and $d$ with the help of formulae (4) for the three wavelength and (5) for the four wavelength approach

- Calculate the logarithm of the Junge coefficient $J_{c}$ by means of the relation: $\log \left(J_{c}\right)=c * t(a v)+d$ 


\section{RETRIEVAL OF SAN DIEGO PSD'S}

The procedure, described in section 4, has been applied to the data, collected in the campaign in San Diego in August 2005 and described in section 3. The results, in terms of the Junge exponent $\mathrm{J}_{\mathrm{e}}$ and the logarithm of the Junge coefficient $\mathrm{J}_{\mathrm{c}}$, are presented in Figures 11 and 12 for the two selected periods of $4 \frac{1}{2}$ days. The values, retrieved from the MSRT data by taking the three wavelength approach, are compared with the PSD's, obtained with the PMS probes at the Naval Subase and the Naval Amphibious Base. It is noted that for the PMS data the PSD's were recorded as dN/dD, so a conversion had to be done to $d N / d R$ by the relation: $\log (d N / d R)=\log \left(J_{c}\right)_{D}+\left(J_{e}-1\right) * \log (R)$ where $\log \left(J_{c}\right)_{D}$ is related to $\mathrm{dN} / \mathrm{dD}$ by the relationship: $\log (\mathrm{dNdD})=\log \left(\mathrm{J}_{\mathrm{c}}\right)_{\mathrm{D}}+\mathrm{J}_{\mathrm{e}} * \log (\mathrm{D})$ and $\mathrm{J}_{\mathrm{e}}$ is the same for $\mathrm{dN} / \mathrm{dR}$ and $\mathrm{dN} / \mathrm{dD}$.

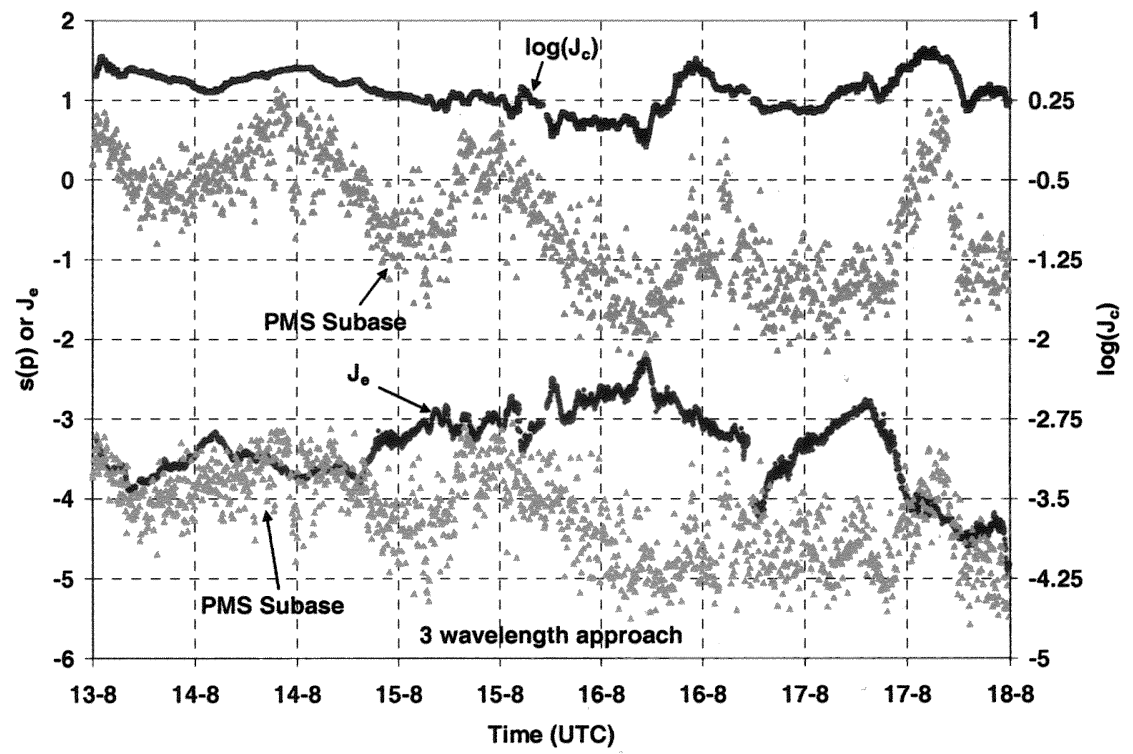

Figure 11. Comparison of $\mathrm{J}_{\mathrm{e}}$ and $\log \left(\mathrm{J}_{\mathrm{c}}\right)$ obtained via retrieval of MSRT data and PMS probe at Subase for 13-17 August

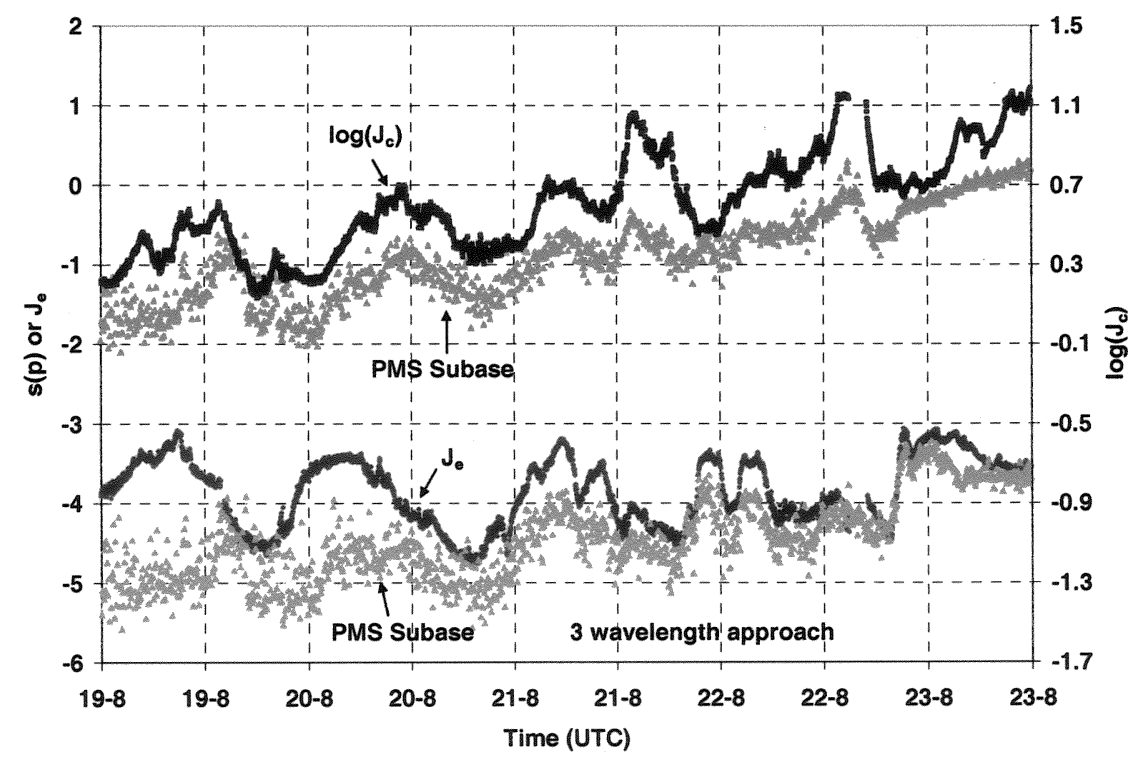

Figure 12. Comparison of $\mathrm{J}_{\mathrm{e}}$ and $\log \left(\mathrm{J}_{\mathrm{c}}\right)$ obtained via retrieval of MSRT data and PMS probe at Subase for 19-23 August 
Figure 11 shows, that the value of $\mathrm{J}_{\mathrm{e}}$, measured with the PMS probe at the Subase, corresponds quite well with the value, retrieved from MSRT data. On the other hand the value of $\log \left(\mathrm{J}_{\mathrm{c}}\right)$ from the PMS probe is generally about 1 less (a factor 10) than that from the MSRT. Apparently the PMS at the Subase site is measuring systematically less bigger particles (radius $1 \mu \mathrm{m}$ ) than are really present in the measurement path. It is evident, that the PMS data show considerably more spread than the MSRT data. On the other hand the PMS data show clearly daily variations of $\log \left(\mathrm{J}_{\mathrm{c}}\right)$ due to the increase of the relative humidity up to $90 \%$ and more around 12.00 (UTC). In Figure 12, we can see a reduction in the spread of the PMS data, due to the fact that the visibility is decreasing and the particle concentration is increasing. The data fit also better to the MSRT data and both plots show very similar fluctuations during this second period. Concerning the Junge exponent $\mathrm{J}_{\mathrm{e}}$ we find sometimes rather big deviations of up to 2 between the PMS and MSRT data, indicating that the correspondence between PMS and MSRT data is better for smaller particles. The slope in the PSD curves for the PMS data is bigger than that of the MSRT data. It is interesting to see if retrieval via the four wavelength approach might result in better agreement. In Figure 13 the difference is shown between the values of $J_{e}$ and $\log \left(J_{c}\right)$ obtained by the three and four wavelength retrieval method. It is clear that the difference between PMS and MSRT becomes smaller for the case of the three wavelength retrieval, as $\mathrm{J}_{\mathrm{e}}$ is nearly always more negative in this case.
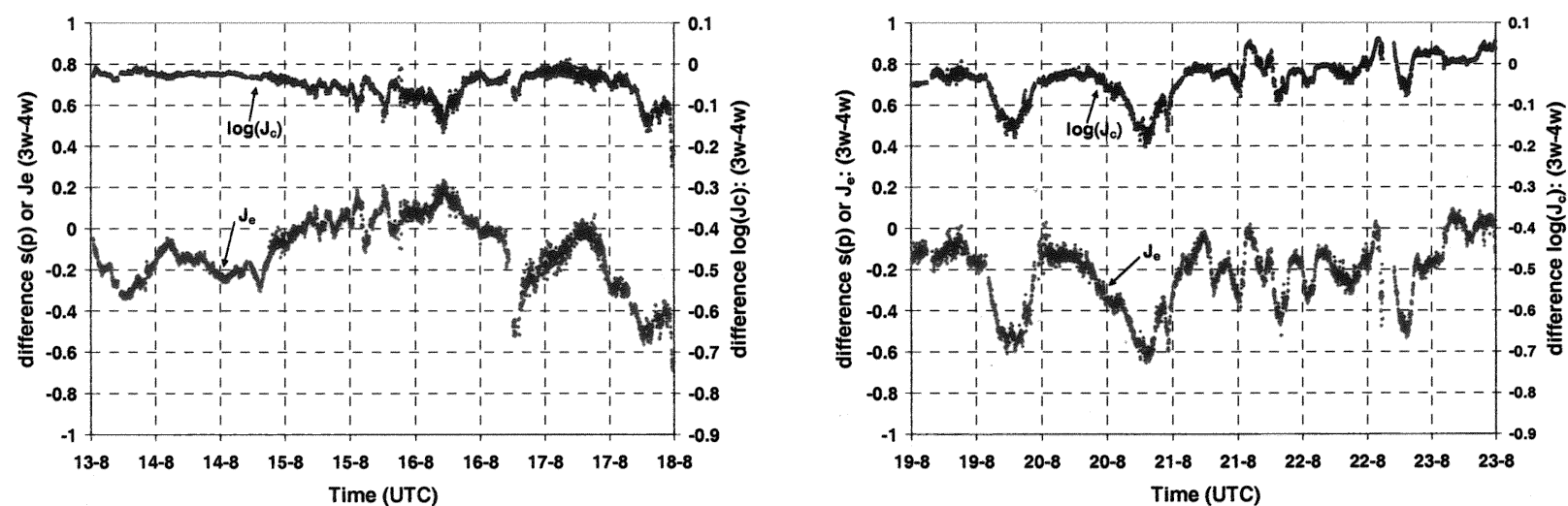

Figure 13. Differences of $\mathrm{J}_{\mathrm{e}}$ and $\log \left(\mathrm{J}_{\mathrm{c}}\right)$, obtained by the three and four wavelength retrieval approaches
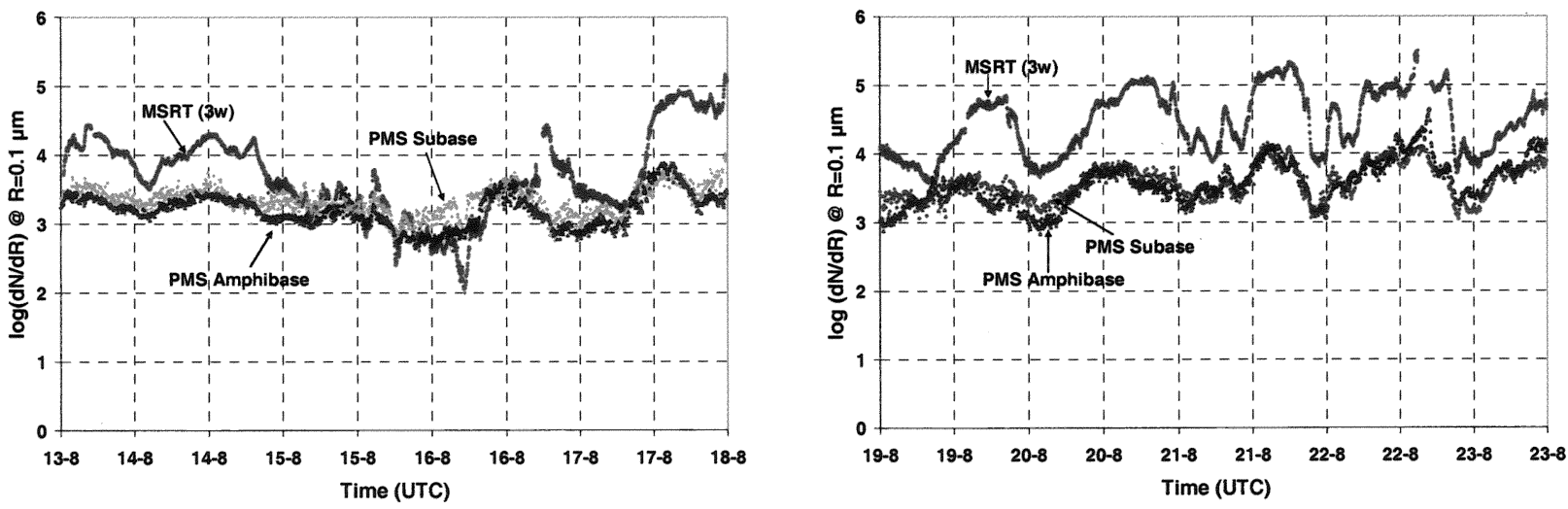

Figure 14. Comparison of the number of particles $\mathrm{dN} / \mathrm{dR}$ at particle radius $\mathrm{R}=0.1 \mu \mathrm{m}$, obtained by retrieval of MSRT data and via extrapolation from the PMS data, collected at the Naval Subase and the Naval Amphibious base

In connection to the number of smaller particles, we have compared $\log (\mathrm{dN} / \mathrm{dR})$ for a particle radius of $0.1 \mu \mathrm{m}$ for the MSRT retrieved data and the PMS data, obtained both at the Naval Subase and the Naval Amphibious base. In this case we simply took the difference between $\log \left(\mathrm{J}_{\mathrm{c}}\right)$ and $\mathrm{J}_{\mathrm{e}}$ for both periods of $4 \frac{1}{2}$ days. The result is shown in Figure 14 , where we find a very good agreement between both PMS data series and even a good match with the MSRT data. It is also clear, that the spread in the PMS data is much less for this particle size and that the general tendency is that the MSRT system measures more particles, than both shore-based PMS systems. 


\section{DISCUSSION AND CONCLUSIONS}

In order to obtain more knowledge of the aerosol characteristics and their influence on infrared and optical sensor performances, we have participated in a transmission measurement campaign over the San Diego Bay with a multi-band transmissometer. According to the theory of scattering, the extinction due to scattering is monotonously decreasing with wavelength, if the majority of the particles is smaller than the wavelength. For the haze, present and returning regularly each day in the Bay area, this was assumed to be the case. The number of bigger particles was low, as these are created in high wind speed conditions, which rarely occurs near San Diego. For this reason it was interesting to develop and test an inversion technique, using the average transmission at three or four wavelengths and the slope of the regression line through each set of transmission values. A tool was developed, based upon a combination of three log-normal PSD's with selectable widths, amplitudes and wavelength centers and for which an approximating Junge distribution was made. This tool was used create a set of conversion formulae, allowing the retrieval of the PSD's of the particles, averaged over the $7.2 \mathrm{~km}$ measurement path. One of the purposes of the experiments was the comparison of the PSD, obtained through this retrieval method, and the PSD's collected in-situ with PMS equipment on both sides of the path.

After introduction of the transmissometer, samples of collected data have been presented, where we have eliminated the contribution of molecular extinction. Errors, introduced in this way are small, as the absolute humidity was practically varying very little during the trials period. Calibration of the sensitivity was done on a day with very good visibility, which was estimated to be $80 \mathrm{~km}$. The data were "cleaned" for obstructions by passing ships and averaged over two minutes in order to reduce the effects of atmospheric turbulence. The remaining data set contains extinction by aerosols only and provides a perfect basis for the retrieval study. It appears that the transmission slopes $s(t)$ are very consistent as long as the average transmission value $t(a v)$ is becoming not below a few percent. Both $s(t)$ and $t(a v)$ are inputs in the conversion process, from which the slope $s(p)$, equivalent to the Junge exponent $J_{e}$, and $\log \left(J_{c}\right)$, where $J_{c}$ is the Junge coefficient, are determined. The estimated accuracy of this procedure is 0.2 , both in $\mathrm{J}_{\mathrm{e}}$ and $\log \left(\mathrm{J}_{\mathrm{c}}\right)$. Apart from the $22^{\text {nd }}$ of August, when the transmission dropped to zero for about half an hour, the retrieved data show very nice rapid changes in PSD characteristics with time. When comparing the retrieval via three and four wavelengths, we conclude that three wavelengths is generally adequate and more accurate at smaller values of $t(a v)$.

The use of three log-normal distributions allows the investigation of anomalous spectral transmission behavior in one of the bands, such as found in the $2.32 \mu \mathrm{m}$ channel. By changing the input characteristics (selecting particles with a radius of $3 \mu \mathrm{m}$ ) in an appropriate way, we could simulate the phenomena found on most of the days around 19.00 (UTC). We have compared the PSD data, retrieved from the MSRT system, with the PMS data. It was found, that the value of $\mathrm{J}_{\mathrm{e}}$ fits reasonably well for moderate visibility conditions (5-50\% transmission). For clear days, the value of $\mathrm{J}_{e}$, obtained from the PMS system is significantly less (about 1 to 2) than that from the MSRT system. At the same times the value of $\log \left(\mathrm{J}_{\mathrm{c}}\right)$, in this case for particles with a radius of $1 \mu \mathrm{m}$, is also about $0.5-1$ less. This is an indication of the less favorable location of the PMS system at the Naval Subase, being in the wind shadow of Point Loma. Another comparison has been made for a particle radius of $0.1 \mu \mathrm{m}$, where we find a perfect agreement in $\log (\mathrm{dN} / \mathrm{dR})$ for both PMS systems, which is somewhat amazing, as one measures in Eastern direction (at the Naval Subase) and the other (on the beach at the Naval Amphibious base) in Western direction. The data, retrieved from the MSRT system, show during most of the time in both periods, a significantly larger number of particles (per $\mu \mathrm{m}$, per $\mathrm{cm}^{3}$ ) than the PMS data. Apparently the conditions at sea are different from the coastal locations. Only at the time of very good visibility (around 06.00 UTC on the $16^{\text {th }}$ ) the number is significantly less than that of the PMS systems.

In conclusion it can be stated, that the retrieval method has great promise in studies on aerosol characteristics. Due to the higher accuracy and more rapid response, smaller variations in PSD characteristics can be determined. The big advantage is the integration of the characteristics over a certain path-length, providing more measurement volume, but also provides data, which are more relevant for EO and IR sensors for detection of targets at sea. It is recommended to use the double source of the MSRT system in eventually future trials, as this source has more radiant intensity in the 4 and $10 \mu \mathrm{m}$ band. It would further be very useful to use a liquid nitrogen filling system, in order to allow continuous measurement in all seven bands of the MSRT system. It is also useful to do the retrieval of the PSD data from the transmission data in-situ and compare it with data from other particle samplers. Finally we would like to thank our host Steve Hammel and his coworkers Dimitri Tsintikidis, Michael Jablecki and Peter Tschmuck for their support and the personnel of the Naval Subase and the Naval Amphibious base for their hospitality during our presence. 


\section{REFERENCES}

[1] Arie N. de Jong et al, Multi-band optical/IR transmissometry during the VAMPIRA trials, spring 2004, SPIE Volume 5572, Optics in Atmospheric Propagation and Adaptive Systems VII, Gran Canaria, September 2004

[2] Arie N. de Jong et al, Two-way multi-band optical/IR transmission measurements in the Persian Gulf-Coastal region, SPIE Volume 5981, Optics in Atmospheric Propagation and Adaptive Systems VIII, Bruges, September 2005

[3] Gerard J. Kunz et al, EOSTAR: an electro-optical sensor performance model for predicting atmospheric refraction, turbulence and transmission in the marine surface layer, SPIE Volume 5237, Optics in Atmospheric Propagation and Adaptive Systems VI, Barcelona, September 2003

[4] F.X. Kneizis et al, The MODTRAN 2/3 report and Lowtran 7 model, Phillips Laboratory, Geophysics Directorate, PL/GPOS, Hanscom AFB, MA 1996

[5] A.M.J. van Eijk et al, The ANAM-3.0 report, TNO report FEL-01-C187, August 2001

[6] Steve Hammel et al, ANAM vs NAM: Is the Difference Significant?, SPIE Volume 5891, Atmospheric Optical Modeling, Measurement and Simulation, San Diego, August 2005

[7] Douglas R. Jensen et al, Electro-optical assessment in coastal environments (EOPACE): summary and accomplishments, Opt. Eng., August 2001

[8] Carl R. Zeisse et al, Measurement of low-altitude infrared propagation, Applied Optics/ 20 February 2000/ Vol. 39, No. 6, pp. 873-886

[9] Stephen M Doss Hammel et al, Low-altitude infrared propagation in a coastal zone: refraction and scattering, Applied Optics/ Vol. 41, No. 18/ 20 June 2002

[10] Arie N. de Jong et al, Long-range transmission at low elevations over the ocean, Proc. Symposium RTO-MP1 on "E-O propagation, signature and system performance under adverse meteorological conditions", Naples, March 1998

[11] Teruyuki Nakajima et al, Retrieval of the optical properties of aerosols from aureole and extinction data, Applied Optics/ Vol.22, No. 19/ October 1983

[12] Oleg Dubovik et al, A flexible inversion algorithm for retrieval of aerosol optical properties from sun and sky radiance measurements, Journal of Geophysical Research, Vol. 105, No. D16, 20.673-20.696, August 27, 2000

[13] W. Michael Farmer, The Atmospheric Filter, Volume 1, Sources; JCD Publishing, Winter Park, FL; 2001

[14] H. Grassl, Determination of Aerosol Size Distributions from Spectral Attenuation Measurements, Applied Optics/ Vol. 10, No. 11/ November 1971

[15] J.D. Klett, Anomalous diffraction model for inversion of multispectral extinction data including absorption effects, Applied Optics, 23, 4499-4508 (1984)

[16] Arie N. de Jong et al, Description of a 7-channel MSRT system: Multi Spectral Radiometer Transmissometer, TNO report FEL-99-I028, February 1999

[17] H.C. van de Hulst, Light Scattering by Small Particles, Dover Publications, 1981 